\title{
INNOVATION MANAGEMENT IN GOOD PRACTICE CONTEXT
}

\author{
Pavel FOBEL \\ Silesian University of Technology \\ University of Matej Bel in Banská Bystrica \\ Tomáš FORGON \\ University of Matej Bel in Banská Bystrica \\ Monika KLIMENTOVÁ FOBELOVÁ \\ $B B C A E$, non-profit organization
}

\begin{abstract}
:
The issue of innovation has also been pursued in social sciences and subsequently specifically in the field of application of socio-scientific knowledge. It is not just about professional engineering ethics but we perceive it in a complex and wider social context. Doing good as well as good practice are more than the professional code of ethics or an effort for technical or managerial excellence. Innovative changes should not be parameterized solely by economic efficiency or performance. With regard to new knowledge and technology development, their ethical aspects become more important and focus more on good life. In the context of social sciences with interdisciplinary trends, applied ethics and its subdisciplines (professional ethics, business ethics, ethics of science and research) can take over and play an important practical role. Innovative processes are increasingly becoming the focus of applied ethics, especially in terms of ethical risks. Our mission is to offer an interdisciplinary view of innovation as discussed in the ethics aspect. Based on these considerations, we conclude that ethics need to be integrated into individual innovation processes and adopted as an important condition for eliminating (mitigating) social risks. In our theoretical considerations we offer a view of the scientific risks and forms of prevention related to innovative change in important areas including engineering practice or health protection.
\end{abstract}

Key words: engineering ethics, ethical advice, innovation and ethics, social science, risks

\section{INTRODUCTION}

Innovations are the subject of many disciplines and practical areas. Therefore, they represent a relatively wide-spectrum interpretation area and extensive application approaches. Interdisciplinary researches in the field of innovations show an increasing interest in participation of social sciences. Still, this issue of socio-science reflection of innovation is perceived as marginal or less significant. It is proven that, with the development of new knowledge and technologies, it is precisely the social science and ethical aspect gaining the importance. It is implied also by the increased emphasis on the practical role of social sciences, the strengthening of soft competencies, the focus on sustainability and social responsibility. At the same time, it implies, in what direction should the social sciences currently present its potential more significantly.

In socio-science discourse, innovations mean the method of action, as "the process of implanting novelty, changing the present social situation" [12]. It therefore touches on social change, social dynamics in its individual areas or the whole system. It is always a combination of invention, innovation competence and innovative motivation. Introducing innovation is always a more demanding process than just continuing in the present activity. It requires a change of stereotypes, communication networks, work organization and managerial approaches, retraining as well as changing of the work styles, and so on. Consequently, it is accompanied by the risk of failure, the danger of accepting the changes, the potential threat to man, nature, recognized thought processes, steady life comfort. It must be seen that the accelerator of innovation is usually market dynamics, a new social order, an effort to be recognized in a competitive environment. As P. Drucker points out, technical, economic and organizational innovation is a necessary condition for the survival of an ever-wider range of economic subjects [3]. Economic leaders demonstrate a commitment to innovation, demonstrating the ambition to push for systematic changes like their prestige, their preferred mission, and organizational priority. In their statements, they emphasize the efforts of companies to apply the latest tools 
and thinking, their determination to offer the products and solutions that improve the world and lives of the people. They believe that innovation differentiates the leader from the follower, and the way we live to that conviction. Therefore, investing in innovations is a preferred value and an important social business card.

\section{INNOVATIVE CHANGES AS AN ETHICAL AMBITION}

The growing importance of innovation in social processes is also becoming an issue of ethics, particularly in terms of its practical role. In this context, we are focusing on innovative changes in terms of their managing and developing new technologies to minimize ethical risks and negative social or environmental impacts requiring ethical significance or ethical caution. Therefore, we place emphasize on ethical monitoring (supervision, audit) and also ethical advisory, expert assistance in assessing or eliminating ethical risks. Methods of application of ethics are more or less elaborated and can therefore be helpful in the implementation strategy of ethics, creation of ethical frameworks, as well as mechanisms of ethical support. In this context, the innovative processes are also becoming an important subject of an application strategy of ethics, particularly in terms of ethical risks, ethical conditions in the preparatory and implementation phase of the innovation changes. In this aspect, we can perceive ethics as a part of innovative changes, if it is not such an innovation itself.

The emphasis on innovation management, including technology innovation, is evident in the area of contemporary business ${ }^{1}$. This issue is the focus of international associations as well as representatives of the top world's companies. Their intention is to implement new type requirements, create high social prestige through ethical responsibility, high credibility, and ecological or social conduct. All transnational events and activities with this thematic focus suggest that the future of sustainable responsible entrepreneurship, including the development of new technologies, also depends on the preference of social and ethical responsibility.

When addressing the issue of innovative changes and its severity, it is most often associated with the field of technology, scientific projects and their application, or economic efficiency. We cannot deny the fact that the actor of these changes is always and/or usually a human being as a rational being with a certain individual ethos and understanding of its team or social mission, or in other words, he/she should be an individual with a certain team role with his creative potential, an application disposition. Even the best innovative intention does not bring about a positive change if it does not meet the condition of applying the human potential and fulfilling a vision that is compatible with the actor's realization options. In addition, the best intention and intent of an innovative change without institutional support loses its value and effectiveness. That is also why the idea gains importance of the character of the innovative intentions, its actors. It is also a fulfilment of a certain vision, strategic frameworks that should have a pro-human nature. The ethical, human risks in the process of creating and implementing the innovative projects are thus becoming an essential aspect of social acceptance, the value acceptability of the innovative goals. In this case, the issue concerns not only new technologies, knowledges and their application but also their ethical evaluation in the context of social changes.

It is also necessary to respect the fact that reliable prevention is a significant stimulus for new knowledge and seeking. It is, therefore, not accidental, that the ambition of personalities associated with technical innovations, with new forms and advanced technologies and technical solutions, ways of management, or a more efficient organization of work is often focused on the prevention of technological risks. Also, the requirements to be met by technical works are usually associated with (human) security, reliability, ethical implications. They are, therefore, related to human failure, lack of recognition of ethical risks and consequences. Ethics is required not only by the scientific progress, application goal but also by the management of the implementation of changes, management sensitivity to innovative changes as well as predictability of consequences, the team-work and operational management interventions in case of the occurrence of problems. Ethical responsibility is therefore rather procedural in character and cannot be subject to simple purpose (finality), commercialization or uncontrolled procedures. This continuous nature of innovative processes should include ethical intent, application flexibility of ethical caution. The new ethical paradigm is a response to the new nature of the risks (social, environmental, technical, value, etc.), their new understanding from ethical responsibility point of view. Therefore, knowledge of the innovation actors should also include training based on values, particularly values of different types, ethical values and values associated with responsibility. Therefore, we can only agree with TA (Technology Assessment) initiatives that participatory activities of these actors "should be linked to what we call the ethos of the profession, i.e. with a set of professional values including the ethical values. This also applies to membership in important decision-making bodies, both legislative and administrative. It would be desirable, to the full extent, to demand such knowledge, value and ethical assumptions from those individuals who seek to be the political representatives of their voters and, of course, all responsible citizens" [10]. Ethics, in the traditional scientific and social paradigm, was perceived rather as an external method of evaluation. Consequences of science and technology have been legitimized in the past and "ethically" justified on the basis of internal rationality. The regulatory function of ethics was lacking because it was taken over by the methodology. By changing the relationship between man, nature, culture, science and technology, it was possible to shift the understanding of ethics of science and technology to the level of new perception of ethics responsibility in the science. Sub-

\footnotetext{
${ }^{1}$ For example, the Canadian "Business Innovation Summit" (http://www.ethicalcorp.com/events) or the Christmas market. Summit RBSWEST held 12-14. 11. 2018 in San Diego with more than 250 CEOs, CSR Vice President of the most innovative American brands, and a range of other major activities held during this period.
} 
sequently, the internal, as well as the external, responsibility of the science was taken into account in relation to other responsible units, i.e. social, cultural-social and economic factors.

In connection with these considerations and the mission of ethics in the current science, the ideas that Ulrich Beck offers to us in his work The Risk Society [2] are inspirational. As a recognized diagnostician of the present age, he points to the fact that sciences have a central role in the modernization process. In a risk society (which U. Beck refers to as "the second modernism" society), the sciences are, unlike the "first modernism", confronted with their own production, results and shortcomings. The science has thus become the cause of risks and today it should take on a new responsibility - to find the solutions to these risks. If he refers to the first wave as a "simple scientization", the latter one should be associated with a "reflective scientization", critical thinking, the ability to identify, critically assess and address complexly intertwined problems. Problems of modernization must be perceived in a new interconnection, "hyper-complexity" and the risk must be perceived as a poly-causal phenomenon. Therefore, our moral mission in science is to overcome sectarianism, narrow specialization, and address the risks from the point of view of the consequences. Otherwise, we remain in positions of prior scientific creation and production of other risks. Although the isolated way of reasoning does not lose its seriousness, it no longer has the capacity to respond to adequate risks of modernization.

It is therefore not surprising that following innovative research and technology, multilateral cooperation programs have emerged. This idea developed within the European Union is referred to as RRI (Research Responsibility and Innovations). RRI is the process that takes into account the potential impact and consequences of research and innovations on the environment and society. Responsible research and innovations are processes carried out by society and for the society. RRI should be a transparent and interactive process in which all social actors (scientists, citizens, politicians, entrepreneurs, non-governmental organizations, etc.) work together throughout the research and innovations process to identify ethical, purposeful and consistent aspects of the scientific-technological results with the society. RRI is now part of a number of European Framework Programs. In Horizon 2020, it is a key part of the program Science in the society [6].

\section{ENGINEERING ETHICS AND A GUARANTEE OF GOOD PRACTICE}

Integrating ethics into the different processes of social life, science, and new technologies is an important condition for eliminating (alleviating) the social risks, assumption their social and moral acceptability, human perspective. Often there is no real innovative activity, creative adaptive approaches. The sense of ethics as a practical wisdom (fronesis) is to create a good life, or everything that supports a better life. Avoided this role and the new mission of ethics and remaining only in the position of declared ethical principles or ethical theories without their application usability would be both socially and professionally incorrect. It is evident that, for example, the impact of a new media is growing, that the issue of human rights is still ethically problematic in connection with the migration processes that the current European society is confronted with the models of Industry 4.0, the global values, the new ecological situation and sustainability, the increasing share of artificial intelligence in all spheres of life, and so on. The ethics must actively respond to these changes in terms of application practice and innovative changes.

In this context, it is more than necessary to promote ethics in new strategies, to integrate it into scientific and engineering practice, development of new technologies and to support its social acceptance. In terms of engineering professions, it will be necessary to implement ethical procedures and standards as well as to find mechanisms for their adoption and assessment. Therefore, we perceive ethics not only as a professional, but also as an organizational and institutional one. Ethics must be considered as a style of work that takes into account not only technological efficiency, economic profitability, but also the external environment - both natural and social. The value congruence of engineering profession should be perceived in terms of all the impacts on society and environment, too. This trend is a guarantee of good practice, a new (innovative) way of performance contributing to the creation a good life in the future. In engineering preparation and practice, we should extend ethical and social sensitivity and its importance for the future. The tool of ethical improvement is not simply the adoption of a code of ethics, but rather its understanding, ways of its practicing, ethical supervision mechanisms (i.e. ethical committee), ways of implementing the code in personal policy, organizational and team visions, etc. Evidence of the necessity of ethical improvement is the present situation related to ethical implementation. We have to say, that "many organizations have their ethical programs, but they do not know what to do with them" [4]. In this case, ethical conduct can be supported by trainings in moral imagination in the frame of engineering profession, presentations and demonstrations of moral dilemmas (e.g. on the Internet communication platform) specific to engineering practice in professional socialization processes, qualifying growth, presentations of good practices, monitoring stakeholders' views, etc. Such shifts of economic or development entities are usually evident when declaring key values that include a certain ethical commitment. A well-set ethical policy of an engineering profession is a prerequisite for good practice and the elimination of social risks in the given environment.

The cohesion of professionalism and coordinated efforts of the actors of changes is an important prerequisite for the all-society and long-term solving of the issues. In principle, we identify with the idea of G. Lipovetsky [7], who points not only to the new trends in ethical effort and so-called third type of ethics, but also his essential idea: "the 21. century will be ethical or will not be at all". Important world institutions (UN), economic analysts and strategists call upon ethical revitalization and caution, and encourage to evaluate the reports of the multinational institutions, inspire the national initiatives (e.g. bringing three ministries 
of happiness and declaration of interest establishment of an analogue state format to more than 100 UN member states) and so on. This also implies that the future and the development of the society will increasingly be confronted with ethical requirements, ethical professional service and professional assistance in this area. Ethics is considered to be an innovative tool, it is a guarantee of good practice and an essential part of a good name (good will willu) of each organization and institution. Some foreign estimates state that this component accounts for up to $80 \%$ of the total cost of the company. In addition, the future is confronted with new challenges, changes and trends that demand new ethical potential. In these contexts, we they deserve the attention of professional help in the field of ethics expertise, which they convincingly justify L. K. Trevino [11], P. Singer [9], R. Rorty [8], P. Werhan [13], and also, others.

\section{ETHICS AS INNOVATIVE STRATEGY IN HEALTHCARE POLICY}

Innovations are often associated with the sphere of technology or knowledge. It is certainly not possible to deny this preference for innovative ambitions, accepting that they are also areas of varying degrees of risk. In the field of health, it is worth mentioning the initiatives of the European Federation of Pharmaceutical Industries and Associations (EFPIA). Its Director-General Richard Bergström points out that right now, thanks to the latest scientific discoveries, we are experiencing an innovative revolution in pharmaceutical industry. According to him, the current trend emphasising patient support requires more cooperation between pharmaceutical companies and the public sector. One of the evidence is a joint program with the European Commission - Innovative Medicines Initiative (IMI) [1].

The philosophy of combining innovative health and ethical ambitions is also implemented through the Slovak branch office AIFP ( Association of Innovative Pharmaceutical Industry). It also confirms, on the basis of verified results, that innovative medicines are constantly shifting the limits of desease control. They prolong and improve people's lives, provide more opportunities for a good life. Although innovation is going through demanding professional research and development, it ultimataly brings benefits to people and the hope for better life. AIFP offers the ability to engage in drug development, administers and receives incentives to improve drugs, verifies their credibility, etc. Innovative initiatives cannot be perceived often purposefully other than what their consequences will be for a person, or in other words they should directly or mediately promote good life, better quality of life, social comfort and social benefits. In these intentions, we understand also new treatment procedures, the use of new technologies in the field of healthcare. From the point of view of innovative strategies, it can be considered ethically dilemmatic, that in medical policy it is often preferred as an innovative transition to new medical practices and the use of new pharmaceuticals. From an ethical point of view, it is ethically controversial whether this transition is purposefully made as an increase of the profit or it actually brings lower costs with the same healing effect for the patient, user or client of these drugs. Serious worries arise from the fact that pharmaceutical companies will bring higher profits and thus the economic parameterization of the pharmaceutical industry is decisive. The appeal to the adequacy of the margins of these companies is ethically legitimate in view of the mission that healthcare facilities and services should fulfil. Therefore, it seems justified to strengthen the institute of ethics committees in healthcare facilities, to extend their role not only in the field of clinical studies but also in the effectiveness of new medical practices, the impact of pharmaceutical influences on medical policy. Healthcare is perceived as systematic and effective activity of the provider of healthcare service for the citizen, or in other words the recipient of this service. Trust to the provider is based on this moral relationship and co-responsibility. Investing in innovative medicinal drugs is underestimated at the expense of the economic margin of pharmaceutical companies. Institutional support for this problematic ethical situation creates the effect of questioning the medical practices, the physician himself as a contact person, the mission of the medical facilities, and the care of human health.

The fact that the medical staff, who is supposed to respect first of all the Hippocrates oath, is in clear contradiction with the treatment and functioning of medical organizations only in the economic context. It follows that healthcare organizations can perceive the ethical culture and functioning of its tools as an innovative policy aimed at the higher quality of health services, the credibility of this humane institution, with a significant impact on the quality of life of the patient and on the work comfort of the employer. At this level, the code of conduct, the creation and functioning of a value-based system (with emphasis on value preferences of medical performance and patient satisfaction), as well as the formation and identification with these values, are based on the creation and enforcement of certain ethical standards and codes of conduct, a culture of doctor-patient relationship, performance focused on the quality of health and the protection of human life. Creating such an ethical culture that maximizes the effectiveness of medical personnel in saving health and human lives is therefore in everyone's interest.

We can also say that the issue in question is not being addressed sufficiently in Slovakia, both in theoretical and practical terms. Although this conceptual approach already has some tradition and verified experiences from abroad, so the current discourse in this area is very modest in contrast to foreign countries and does not respond to the extent to which the topic deserves it, at the present time. In some ways, it lags behind the current discourse and does not respond to these challenges or innovative possibilities. Even if it becomes the subject of discussion or professional reflection, it is more so in the economic aspect or narrowly specialized field of specialists in the field of healthcare. This is a multidisciplinary problem and requires a more complex interdisciplinary understanding. From this point of view, a suitable theoretical platform is created by applied ethics which is capable of offering a deeper understanding and the most appropriate response in this interdisciplinary aspect. 
Also, on the practical level, the significant underestimation of this issue can be noted, a solution of which would increase the performance potential of the staff, the more efficient use of new technologies and health practices, motivational behaviour or the loyalty of medical staff. E.g. insufficient attention is paid to the transformation of medical facilities. It is underestimated in the preparation of responsible subjects, management of medical facilities, legislative framework, recruitment of new employees, work of employees and mechanisms of their support. A risk phenomenon that affects ethical culture in medical facilities and their trust is often also the entry of the politics into the decisionmaking mechanisms, the impact of business subjects, high bureaucratic difficulty, which limits the real healthcare performance, dependence on economic performance and not quality of the service. The portfolio of risk areas and processes in the healthcare system is internally interconnected and requires ethical support, comprehensive solutions and ethical supervision. Many of these, the patients, as well as partners, perceive only from the outside, real manifestations, as a certain complex failing, with has usually obvious identifying features of the actors and cause. There is no longer a protective support mechanism. Therefore, in the ethics and implementation of its instruments, there is a great opportunity for positive change, overcoming problem and risk factors. Innovation is also about accepting these new challenges in the field of health, care for man and the quality of his life.

\section{CONCLUSION}

At present, innovation processes are rather accelerating than slowing down, at the same time rather expanding than particularizing. Therefore, it is necessary to accept the polydimensionality of innovative changes with the participation of social sciences, interdisciplinary. As the diagnostic of our time, A. Giddens points out: "In the form of biotechnology, they influence the technical progress by our own physical form as human beings, as well as the natural environment in which we live ... the humanization of technology will probably mean growing exercitation of the moral issues" [5]. We are convinced that we will be increasingly confronted with ethical issues in innovative processes their

\section{prof. PhDr. Pavel Fobel, PhD.}

Silesian University of Technology

Faculty of Organization and Management

ul. Roosevelta 26-28, 41-800 Zabrze, Poland

University of Matej Bel in Banská Bystrica

Department of Ethics and Applied Ethics

Tajovského 40, 97401 Banská Bystrica, Slovak Republic

e-mail: Pavel.Fobel@umb.sk

\section{MUDr. Tomáš Forgon, MPH}

University of Matej Bel in Banská Bystrica

Department of Ethics and Applied Ethics

Tajovského 40, 97401 Banská Bystrica, Slovak Republic

e-mail: tforgon@gmail.com management and evaluation. In this context, we also perceive the social mission of applied ethicists, i.e. their important role to participate in these new challenges.

\section{ACKNOWLEDGMENT}

The authors would like to thank Agency APVV for their support of the APVV-17-0400 project "Enhancing the Ethical Environment in Slovakia (Institutional Procedures, Actors, Risks, Strategies)". This article was created as part of the project.

\section{REFERENCES}

[1] AIFP. Asociácia Inovatívneho Farmaceutického Priemyslu. Internet: http://www.aifp.sk/sk/etika/, Dec. 5, 2013 [Dec. 26, 2018].

[2] U. Beck. Riziková společnost'. Na ceste $k$ jiné moderně. Praha: SLON, 2004.

[3] F.P. Drucker. Innovation and Entrepreneurship. New York: Harper Collins Publishers, 1985.

[4] P. Fobel et al. Organizačná etika a profesionálne poradenstvo. Banská Bystrica: Žiar nad Hronom, 2013, p. 43.

[5] A. Giddens. Důsledky modernity. Praha: SLON, 1988.

[6] A. Kuzior. „Development of competences key to sustainable development". Zeszyty Naukowe Politechniki Ślqskiej. Organizacja i Zarzqqdzanie, z. 75, pp. 71-81, 2014.

[7] G. Lipovetsky. Soumrak povinnosti. Praha: Vydavatel'stvo Prostror, 1999.

[8] R. Rorty. „Philosophy's Role Vis-à-vis Business Ethics“. Business Ethics Quarterly, vol. 16, no. 3, pp. 369-380, 2006.

[9] P. Singer. Spisy o etickom žití. Bratislava: Vydavatel'stvo spolku slovenských spisovatel'ov, 2000.

[10] L. Tondl. Hodnoty, komunikácia, múdrost: Výber vedeckých diel od Ladislava Tondla pre aplikovanú etiku. Banská Bystrica: Vydavatel'stvo Univerzita Mateja Bela Belianum, 2014.

[11] L.K. Trevino and M.E. Brown. „Managing to be ethical: Debunkingfive business ethics myth". Academy of Management Executive, vol. 18, no. 2, pp. 69-81, 2004.

[12] J. Linhart, M. Petrusek, A. Vodáková and H. Maříková. Velký sociologický slovník. Praha: Vydavatel'stvo Karolinum, 1996.

[13] P.H. Werhane. „A Place for Philosophers in Applied Ethics and the Role of Moral Reasoning in Moral Imagination: A Response to Richard Rorty". Business Ethics Quarterly, vol. 16, no. 3, pp. 381-389, 2006.

Mgr. Monika Klimentová Fobelová, PhD. BB CAE, non-profit organization, Slovak Republic e-mail: klimentova.monika5@gmail.com 